\title{
ANALISIS PENGARUH CAMPURAN BAHAN BAKAR PERTALITE DENGAN NAPHTHALENE TERHADAP KONSUMSI BAHAN BAKAR, TORSI DAN DAYA PADA SEPEDA MOTOR 4 LANGKAH
}

\author{
Oleh \\ I.K. Suka Arimbawa1', I.N. Pasek Nugraha ${ }^{1}$, K. Rihendra Dantes ${ }^{2}$ \\ Program Studi Pendidikan Teknik Mesin \\ Jurusan Teknologi Industri, Fakultas Teknik dan Kejuruan \\ Universitas Pendidikan Ganesha \\ Singaraja, Indonesia \\ e-mail: dedex.ari@gmail.com, paseknugraha@undiksha.ac.id, rihendra- \\ dantes@undiksha.ac.id
}

\begin{abstract}
Abstrak
Penelitian ini bertujuan untuk mengetahui pengaruh campuran bahan bakar pertalite dengan Naphthalene terhadap konsumsi bahan bakar, torsi dan daya pada sepeda motor 4 langkah. Data yang diamati pada penelitian ini adalah perbandingan konsumsi bahan bakar, torsi dan daya yang dihasilkan oleh sepeda motor 4 langkah. Pada penelitian ini, penulis lebih memilih untuk menggunakan metode penelitian dengan metode eksperimen. Hasil dari penelitian ini yaitu, bahan bakar pertalite murni didapatkan konsumsi bahan bakar sebesar $0,576 \mathrm{~kg} / \mathrm{jam}$, torsi $7,11 \mathrm{~N} . \mathrm{m}$, dan daya 6,45 Hp. Data rata-rata dari campuran bahan bakar 1 liter pertalite dengan 5 gram Naphthalene didapatkan konsumsi bahan bakar 0,352 kg/jam, torsi 7,56 N.m, daya 6,77 $\mathrm{Hp}$. Bahan bakar 1 liter pertalite dengan 10 gram Naphthalene didapatkan konsumsi bahan bakar $0.342 \mathrm{~kg} / \mathrm{jam}$, torsi 7,86 N.m, dan daya 6,97 Hp. Dari penelitian ini didapatkan hasil, Campuran bahan bakar 1 liter pertalite dengan 10 gram Naphthalene terbaik untuk konsumsi bahan bakar, torsi dan daya dibandingkan bahan bakar pertalite murni dan campuran 1 liter pertalite dengan 5 gram Naphthalene.
\end{abstract}

Kata kunci: konsumsi bahan bakar, daya,torsi, Naphthalene, pertalite.

\section{Abstract}

This study aims to determine the effect of a mixture of pertalite fuel and Naphthalene on fuel consumption, torque and power on a 4-step motorcycle. The data observed in this study is a comparison of fuel consumption, torque and power produced by a 4-step motorcycle. In this study, the authors prefer to use research methods with experimental methods. The results of this study, namely, pure pertalite fuel obtained fuel consumption of $0.576 \mathrm{~kg} /$ hour, torque of $7.11 \mathrm{~N} . \mathrm{m}$, and power of $6.65 \mathrm{Hp}$. The average data from the 1 liter pertalite fuel mixture with 5 grams of Naphthalene obtained fuel consumption of $0.352 \mathrm{~kg} /$ hour, torque of $7.56 \mathrm{~N} . \mathrm{m}$, power of $6.77 \mathrm{hp}$. Fuel of 1 liter of pertalite with 10 grams of Naphthalene obtained fuel consumption of $0.342 \mathrm{~kg} /$ hour, torque of $7.86 \mathrm{~N} . \mathrm{m}$, and power of $6.97 \mathrm{hp}$. The results of this study showed that the best 1 liter pertalite with 10 grams of Naphthalene fuel mixture is best for fuel consumption, torque and power compared to pure pertalite fuel and a 1 liter pertalite mixture with 5 grams Naphthalene.

Keywords: fuel consumption, power, torque, Naphthalene, pertalite.

\section{PENDAHULUAN}

Kendaraan merupakan sebuah alat transportasi yang digunakan secara masal oleh semua kalangan masyarakat untuk memudahkan dalam melakukan atau bepergian ke suatu tempat. Jumlah kendaraan di Indonesia setiap tahun semakin meningkat sehingga menyebabkan kepadatan lalu lintas. Berdasarkan Badan Pusat Statistika 
(2016), menunjukkan indikasi peningkatan pada sepeda motor dari tahun 2012 sebesar 76.381.183 unit sepeda motor, tahun 2013 sebesar 84.732.652 unit sepeda motor, tahun 2014 sebesar 92.976.240 unit sepeda motor, tahun 2015 sebesar 98.881.267 unit sepeda motor, dan tahun 2016 sebesar 105.150 .082 unit sepeda motor.

Banyaknya kendaraan bermotor keluaran saat ini dengan rasio kompresi antara 9:1-11:1 harus didukung bahan bakar yang beroktan tinggi agar tidak terjadi knocking atau detonasi dalam ruang bakar akibat tekanan kompresi yang tinggi. Seharusnya penggunaan bahan bakar disesuaikan rasio kompresi. Karena terlalu rendah spesifikasi bahan bakar akan mengakibatkan tenaga berkurang, sedangkan jika terlalu tinggi tidak maksimal tenaganya.

Sementara itu dengan semakin menipisnya cadangan bahan bakar minyak (BBM) yang merupakan bahan bakar fosil yang menurut sifatnya termasuk bahan bakar tak-terbaharukan. penggunaan bahan bakar alternatif menjadi sangat penting dan tidak dapat dihindarkan lagi jika tidak ingin menjadi krisis energi yang serius. Salah satu bahan bakar alternatif yang di maksudkan disini adalah penambahan Naphthalene (kapur barus) pada bahan bakar pertalite, hal ini bisa mendapatkan konsumsi bahan bakar yang irit dan performa mesin yang optimal. Penulis menggunakan alat uji Dynotest untuk mengukur torsi dan daya.

Torsi adalah ukuran kemampuan mesin untuk melakukan kerja. Torsi merupakan parameter yang baik dalam menentukan prestasi dari mesin, torsi didefinisikan sebagai gaya yang bekerja pada jarak sesaat dengan satuan $(\mathrm{Nm})$ atau (lbf.ft).Torsi dirumuskan sebagai berikut:

$$
\mathrm{Tr}=\mathrm{F} . \mathrm{r}
$$

Dimana:

$\mathrm{T}=$ Torsi benda berputar (N.m)

$F=$ gaya sentrifugal dari benda yang berputar $(\mathrm{N})$

$r=$ jarak benda ke pusat rotasi/jari-jari (m)

Daya motor merupakan salah satu parameter dalam menentukan performa motor. Dengan demikian jumlah putaran (rpm) dan besarnya momen putar atau torsi mempengaruhi daya yang dihasilkan oleh sebuah motor. Daya dirumuskan sebagai berikut:

Keterangan :

$$
\mathrm{P}=\frac{2 \pi \cdot n \cdot T}{60000}(\mathrm{~kW})
$$

$$
\begin{array}{ll}
\mathrm{P} & \text { : Daya }(\mathrm{kW}) \\
\mathrm{T} & \text { : Torsi }(\mathrm{Nm}) \\
\mathrm{n} & \text { : Banyak putaran permenit (RPM) } \\
& \text { Konsumsi bahan bakar mf diartikan }
\end{array}
$$

sebagai jumlah bahan bakar yang dipergunakan oleh kendaraan dalam rentan waktu. Konsumsi bahan bakar mf dapat dihitung menggunakan persamaan sebagai berik ıt *

$$
m f=\frac{\rho \times V f \times 10^{-3}}{t f} \times 3600
$$

Dimana :

$$
\begin{aligned}
m f= & \text { Konsumsi bahan bakar ( } \mathrm{kg} / \mathrm{jam}) \\
\rho= & \text { massa jenis pertalite adalah } 0,77 \\
V f= & \text { Volume bahan bakar yang diuji (ml) } \\
t f= & \text { Waktu untuk menghabiskan bahan } \\
& \text { bakar yang diuji (s) } \\
& \text { Pertalite adalah bahan bakar }
\end{aligned}
$$
minyak terbaru dari Pertamina dengan RON 90. Pertalite dihasilkan dengan penambahan zat aditif dalam proses pengolahannya di kilang minyak. Pertalite diluncurkan tanggal 24 Juli 2015 sebagai varian baru bagi konsumen yang menginginkan BBM dengan kualitas di atas Premium, tetapi dengan harga yang lebih murah dari pada Pertamax.

Naphthalene adalah hidrokarbon kristlalin aromatik berbentuk padatan berwarna putih dengan rumus molekul $\mathrm{C} 10 \mathrm{H} 8$ dan berbentuk dua cincin benzena yang bersatu. Senyawa ini bersifat volatil, mudah menguap walau dalam bentuk padatan. Uap yang dihasilkan bersifat mudah terbakar. Naphthalene memiliki kemiripan sifat yang memungkinkan menjadi aditif pertalite untuk meningkatkan angka oktan. Sifat-sifat tersebut antara lain: sifat pembakaran baik, mudah menguap sehingga tidak meninggalkan getah padat pada bagianbagian mesin.

\section{METODE}


Pada penelitian ini, penulis lebih memilih untuk menggunakan metode penelitian dengan metode eksperimen. Obyek utama dalam penelitian ini yaitu motor bakar 4 langkah yang yaitu Honda Vario CW 110. Adapun bahan yang digunakan dalam penelitian ini adalah bahan bakar pertalite dan naphthalene.

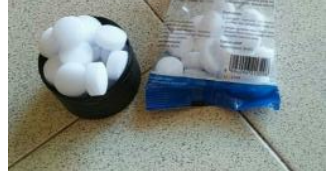

Gambar 1 Zat Naphthalene (kapur barus)

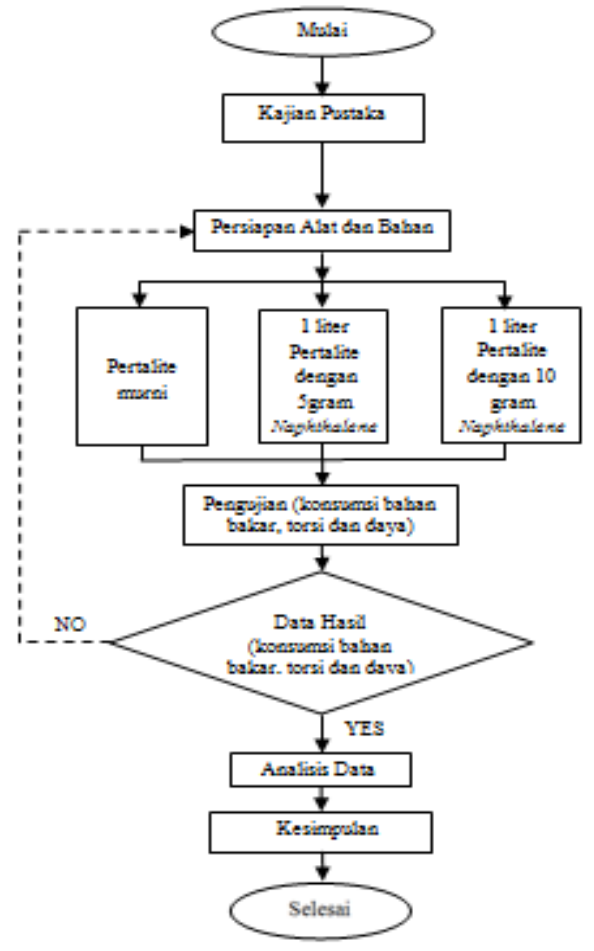

Gambar 2 Diagram Alir

Prosedur Pengujian a) persiapan alat dan bahan, menyalakan alat dynotest dan memasang sensor

b) Menghidupkan mesin dan pengecekan serta melakukan percobaan.

c) Motor dengan menggunakan campuran bahan bakar pertalite murni,5 gram naphthalene dan 10 gram naphthalene dilakukan pengujiaan.

d) Setelah pengujian secara berurutan pada masing-masing campuran pada alat uji mencapai torsi dan daya pada rpm tertentu pengambilan data selesai (memperhentikan proses pengambilan data pada dynotest).

e) Mematikan motor.

f) persiapan alat dan bahan, menyalakan alat untuk pengujian konsumsi bahan bakar dengan volume $50 \mathrm{ml}$ pada masing-masing campuran.

g) Motor dengan menggunakan campuran bahan bakar pertalite murni,5 gram naphthalene dan 10 gram naphthalene dilakukan pengujiaan.

h) Setelah bahan bakar dengan volume $50 \mathrm{ml}$ habis dan mencapai waktu pada rpm tertentu pengambilan data selesai (memperhatikan pengambilan data pada stopwatch).

i) mencatat hasil pencapaian waktu pada masing-masing campuran.

j) Mematikan motor

k) Cabut sensor alat pengujian, dan matikan alat dan mesin motor, Pengujian selesai.

\section{HASIL DAN PEMBAHASAN}

Hasil Pengujian Konsumsi Bahan Bakar

Pada hasil pengujian konsumsi

bahan bakar dan setelah melakukan proses perhitungan maka data yang diperoleh dapat dilihat pada tabel dan grafik berikut ini:

Tabel 1. Rata-rata Konsumsi Bahan Bakar

\begin{tabular}{|c|c|c|c|}
\hline \multirow{2}{*}{ Putaran Mesin } & \multicolumn{3}{|c|}{ Konsumsi bahan bakar (kg/jam) } \\
\cline { 2 - 4 } & Pertalite Murni & 5 gram & 10 gram \\
\hline 4000 & 0,380 & 0,278 & 0,269 \\
\hline 5000 & 0,439 & 0,310 & 0,301 \\
\hline
\end{tabular}




\begin{tabular}{|c|c|c|c|}
\hline 6000 & 0,561 & 0,345 & 0,338 \\
\hline 7000 & 0,612 & 0,369 & 0,361 \\
\hline 8000 & 0,680 & 0,390 & 0,381 \\
\hline 9000 & 0,786 & 0,423 & 0,405 \\
\hline Rata-rata & $\mathbf{0 , 5 7 6}$ & $\mathbf{0 , 3 5 2}$ & $\mathbf{0 , 3 4 2}$ \\
\hline
\end{tabular}

Hubungan Putaran Mesin Dengan Konsumsi Bahan Bakar

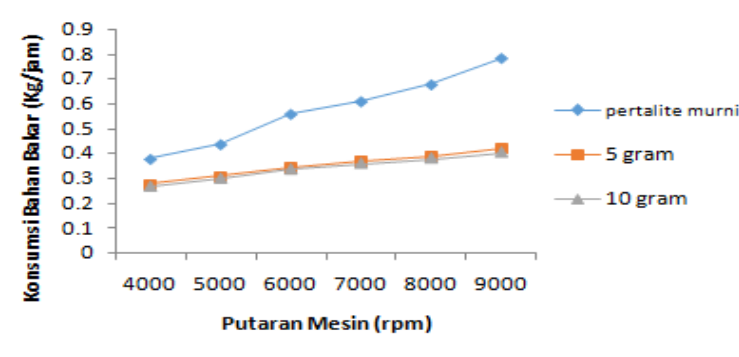

Gambar 3

Grafik rata-rata konsumsi bahan bakar dari 4000 rpm sampai 9000 rpm

Berdasarkan hasil uji yang dilakukan didapatkan hasil yaitu rata-rata konsumsi bahan bakar yang dihasilkan pada saat menggunakan campuran bahan bakar pertalite dengan naphthalene didapatkan hasil yaitu bahan bakar pertalite murni sebesar 0,576 $\mathrm{kg} / \mathrm{jam}$, Campuran bahan bakar 1 liter pertalite dengan 5 gram naphthalene sebesar
0,352 kg/jam, dan Campuran bahan bakar 1 liter pertalite dengan 10 gram naphthalene sebesar $0.342 \mathrm{~kg} / \mathrm{jam}$.

Dari perbedaan diatas, dapat disimpulkan bahwa penggunaan campuran zat naphthalene lebih baik dibandingkan menggunakan campuran zat naphthalene. Ini dikrenakan di dalam bahan bakar tersebut terjadi perubahan kandungan unsur senyawanya, yakni atom oksigen yang terkandung dalam naphthalene akan bercampur dengan bahan bakar sehingga kadar oksigen pada campuran bahan bakar dan udara akan meningkat yang akan menghasilkan suasana pembakaran yang lebih baik.

Pengujian Torsi

Dari hasil pengujian Torsi diperoleh data dalam bentuk tabel dan grafik sebagai berikut:

Tabel 1. Rata-rata Torsi

\begin{tabular}{|c|c|c|c|}
\hline \multirow{2}{*}{ Putaran Mesin } & \multicolumn{3}{|c|}{ Torsi } \\
\cline { 2 - 4 } & Pertalite Murni & 5 gram & 10 gram \\
\hline 4000 & 7,19 & 7,72 & 8,59 \\
\hline 5000 & 9,63 & 9,83 & 10,38 \\
\hline 6000 & 8,17 & 8,53 & 8,70 \\
\hline 7000 & 7,16 & 7,61 & 7,72 \\
\hline 8000 & 6,16 & 6,56 & 6,78 \\
\hline 9000 & 4,39 & 4,89 & 5,01 \\
\hline Rata-rata & $\mathbf{7 , 1 1}$ & $\mathbf{7 , 5 2}$ & $\mathbf{7 , 8 6}$ \\
\hline
\end{tabular}

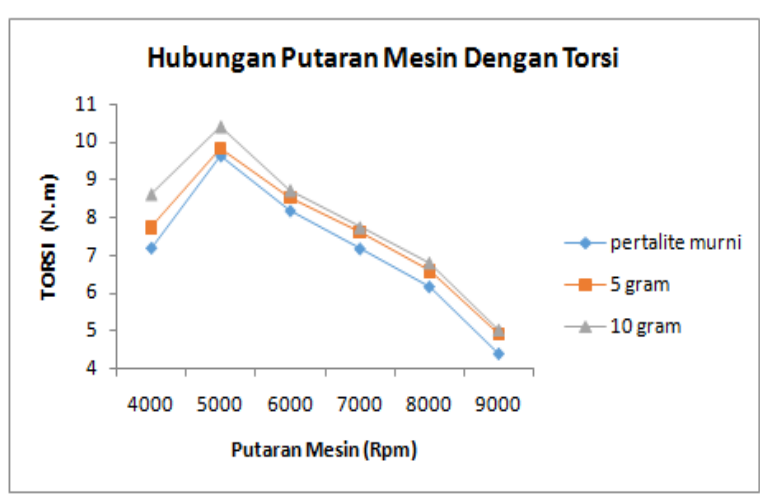

Gambar 4

\section{Grafik Rata-Rata Torsi dari RPM 4000 Sampai RPM 9000}

pada $\begin{gathered}\text { Rata-rata torsi yang dihasilkan } \\ \text { sepeda motor dengan }\end{gathered}$ mengguanakan campuran bahan bakar pertalite murni torsi didapatkan 7,48 N.m pada. Sedangkan campuran bahan bakar 1 liter pertalite dengan 5 gram naphthalene menghasilkan rata-rata torsi 
sebesar 7.56 N.m. Serta campuran bahan bakar 1 liter pertalite dengan 10 gram naphthalene menghasilkan rata-rata torsi sebesar 7.86 N.m.

Dari hasil pengujian Torsi yang dilakukan pada kendaraan sepeda motor Honda Vario cw 110 cc, menghasilkan torsi dari kecil kemudian naik dan mengalami penurunan setelah torsi maksimal seiring bertambahnya putaran mesin.. Penurunan torsi pada putaran tinggi ini terjadi disebabkan oleh pengaruh jumlah bahan bakar dan udara yang masuk ke ruang bakar cenderung berkurang seiring dengan semakin naik putaran mesin. Hal ini berkaitan dengan campuran bahan bakar dan udara yang masuk ke dalam silinder tidak sempurna pada saat putaran mesin tinggi. Pada saat putaran tinggi terjadi floating pada katup hisap dan katup buang, dimana floating ini merupakan suatu keadaan pada katup hisap dan katup buang tidak menutup secara sempurna disebabkan oleh waktu yang sangat singkat seiring tingginya putaran mesin.

Hasil Pengujian Daya

Dari hasil pengujian daya diperoleh data dalam bentuk tabel dan grafik sebagai berikut:

Tabel 1. Rata-rata Daya

\begin{tabular}{|c|c|c|c|}
\hline \multirow{2}{*}{ RPM } & \multicolumn{3}{|c|}{ Daya } \\
\cline { 2 - 4 } & Pertalite Murni & 5 gram & 10 gram \\
\hline 4000 & 4,16 & 4,52 & 5,02 \\
\hline 5000 & 7,08 & 7,22 & 7,36 \\
\hline 6000 & 7,06 & 7,4 & 7,54 \\
\hline 7000 & 7,24 & 7,66 & 7,78 \\
\hline 8000 & 7,52 & 7,58 & 7,8 \\
\hline 9000 & 5,64 & 6,36 & 6,42 \\
\hline Rata-rata & $\mathbf{6 , 4 5}$ & $\mathbf{6 , 7 7}$ & $\mathbf{6 , 9 7}$ \\
\hline
\end{tabular}

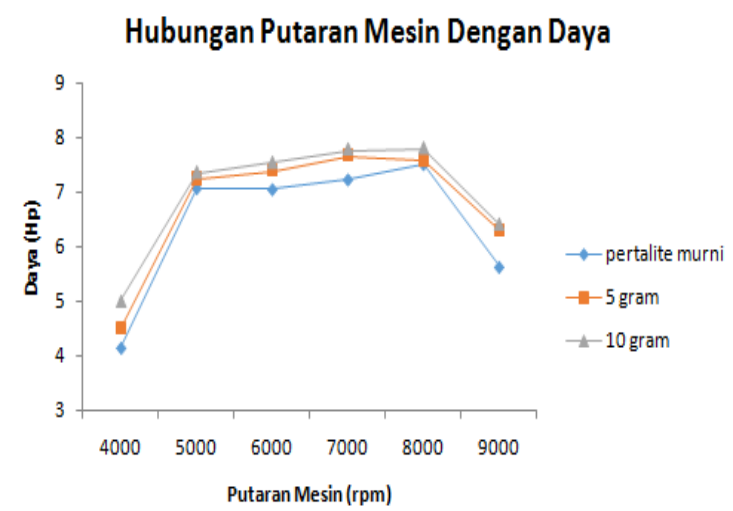

Gambar 5

Grafik Rata-Rata Torsi dari RPM 4000 Sampai RPM 9000

pada $\begin{gathered}\text { Rata-rata daya yang dihasilkan } \\ \text { sepeda motor dengan }\end{gathered}$ mengguanakan campuran bahan bakar pertalite murni daya didapatkan 6,65 $\mathrm{Hp}$. Sedangkan campuran bahan bakar 1 liter pertalite dengan 5 gram naphthalene menghasilkan rata-rata daya sebesar 6,77 Hp. Serta campuran bahan bakar 1 liter pertalite dengan 10 gram naphthalene menghasilkan rata-rata daya sebesar 6.97 $\mathrm{Hp}$.

Dapat dilihat bahwa adanya perbedaan hasil pengujian daya pada setiap masing-masing variasi campuran, pada hasil pengujian daya efektif meningkat, kemudian menurun setelah daya maksimal di capai seiring dengan bertambahnya putaran mesin. Daya yang dihasilkan oleh suatu kendaraan akan dipengaruhi oleh torsi dan rpm pada kendaraan tersebut. Jika torsi naik, maka daya dari kendaraan tersebut akan naik juga, tetapi setelah torsi mencapai nilai maksimalnya, torsi akan menurun namun daya yang dihasilkan belum tentu mengalami penurunan disebabkan rpm yang semakin tinggi. Pada hal ini daya yang dihasilkan suatu kendaraan berbanding lurus dengan torsi yang dihasilkan oleh kendaraan tersebut.

Dalam penelitian ini menganalisis datanya yaitu setelah mendapatkan hasil 
dari pengujian konsumsi bahan bakar, kemudian pengujian torsi dan daya menggunakan dynotest.

Uji Hipotesis

Uji hipotesis pada penelitian ini menggunkan uji manova. Uji manova

\section{SIMPULAN DAN SARAN}

Adapun kesimpulan yang dapat penulis berikan dari pengaruh perbandingan penggunaan ampuran bahan bakar pertalite murni, 5 gram naphthalene, dan 10 gram naphthalene terhadap konsumsi bahan bakar, torsi dan daya pada sepeda motor.

1. Terdapat perbedaan konsumsi bahan bakar antara campuran bahan bakar pertalite murni, 5 gram naphthalene, dan 10 gram naphthalene. Hal ini dibuktikan oleh hasil rata-rata konsumsi bahan bakar campuran bahan bakar 1 liter pertalite dengan pertalite murni sebesar 0,576 $\mathrm{kg} / \mathrm{jam}$, campuran bahan bakar 1 liter pertalite dengan 5 gram Naphthalene sebesar 0,352 kg/jam, dan campuran bahan bakar 1 liter pertalite dengan 10 gram Naphthalene sebesar $0.342 \mathrm{~kg} / \mathrm{jam}$.

2. Terdapat terdapat perbedaan torsi antara campuran bahan bakar pertalite murni , 5 gram naphthalene, dan 10 gram naphthalene. Hal ini dibuktikan dengan hasil rata-rata torsi bahan bakar pertalite murni didapatkan 7,11 N.m. Sedangkan campuran bahan bakar 1 liter pertalite dengan 5 gram Naphthalene menghasilkan rata-rata torsi sebesar 7.52 N.m. Serta campuran bahan bakar 1 liter pertalite dengan 10 gram Naphthalene menghasilkan rata-rata torsi sebesar 7.86 N.m.

3. Terdapat terdapat perbedaan daya antara campuran bahan bakar pertalite murni, 5 gram naphthalene, dan 10 gram naphthalene. Hal ini dibuktikan dengan hasil rata-rata daya bahan bakar pertalite murni didapatkan 6,45 Hp. Sedangkan campuran bahan bakar 1 liter pertalite dengan 5 gram Naphthalene menghasilkan rata-rata daya sebesar 6,77 Hp. Serta campuran bahan bakar 1 liter pertalite dengan 10 gram Naphthalene menghasilkan rata-rata daya sebesar $6.97 \mathrm{Hp}$.

Adapun saran yang penulis dapat di sampaikan adalah sebagai berikut: digunakan untuk menentukan apakah terdapat perbedaan signifikan secara statistik pada beberapa variabel yang terjadi secara serentak antara dua tingkatan dalam satu variabel.

1. Untuk memperoleh hasil yang lebih akurat baik ditinjau dari pengaruhnya terhadap performasi perlu penelitian lebih lanjut tentang pengaruh kadar campuran pertalite dan naphthalene dengan menggunakan engine lebih dari satu jenis.

2. Pengujian sebaiknya dilakukan di tempat yang memang ahli dalam bidang tersebut untuk memperkecil kemungkinan terjadinya human eror.

\section{DAFTAR PUSTAKA}

Ahmad Gurnit, Bambang Sudarmanta. 2016. Pengaruh Ignition Timing Mapping Terhadap Unjuk Kerja Dan Emisi Engine Sinjai 650 cc Berbahan Bakar Pertalite Ron 90.

Fintas Afan Agrariksa. 2013. Uji Performansi Motor bakar Bensin (On Chassis) Menggunakan Campuran Premium dan Etanol. Fakultas Teknologi Pertanian-Universitas Brawijaya.

I Wayan Budi Artawan, I.G.B. Wijaya Kusuma, Dan I.W. Bandem Adnyana (2016). Pengaruh Penggunaan Bahan Bakar Pertalite Terhadap Unjuk Kerja Daya, Torsi, Dan Konsumsi Bahan Bakar Pada Sepeda Motor Bertransmisi Otomatis. Fakultas Teknik Udayana.

Pt. Pertamina Indonesia. 2015. Pengertian Dan Keunggulan Bahan Bakar Pertalite. Jakarta Indonesia.

Pasek Nara Wiryawan. 2017. Pengaruh Perbandingan Penggunaan Bahan Bakar Gas LPG Dan Bahan Bakar Pertalite Terhadap Unjuk Kerja Motor Bakar Bensin 4 Pada Motor Honda Supra Fit.

Tinus Ginting. (2017). Analisa Pengaruh Campuran Premium Dengan Kapur Barus (Naphthalene) Terhadap Emisi Gas Buang Pada Mesin Supra X 125 Cc. Akademi Teknologi Industri Imanuel Medan. 